\title{
Stage II Cutaneous Squamous Cell Carcinoma of the Head and Neck AJCC v8
}

National Cancer Institute

\section{Source}

National Cancer Institute. Stage // Cutaneous Squamous Cell Carcinoma of the Head and Neck A/CC v8. NCI Thesaurus. Code C133257.

Stage II includes: T2, N0, M0. T2: Tumor $2 \mathrm{~cm}$ or larger, but smaller than $4 \mathrm{~cm}$ in greatest dimension. N0: No regional lymph node metastasis. M0: No distant metastasis. (AJCC 8th ed.) 